\title{
SWOT Analysis and Countermeasures for the Development of Wudang Mountain Martial Arts Tourism Industry
}

\author{
Yi Ke ${ }^{1, *}$ \\ ${ }^{1}$ School of Physical Education and Equestrian, Wuhan Business University, Wuhan, China
}

\begin{abstract}
Through research methods such as expert interviews and field studies, this author believes that under the policy opportunity of the country vigorously promoting the development of sports tourism industry, Wudang Mountain, as a well-known scenic spot and a famous Taoist mountain, should seize the opportunity to deeply integrate martial arts (Wushu) elements into the regional tourism industry and create a composite multi-layer Wushu tourism industry pattern to better promote the industrial development. By giving full play to its own advantages and making up for its own shortcomings, Wudang Mountain will be able to achieve the goal of transformation and upgrading of the region's tourism industry and open up new horizons for the development of Wudang Wushu tourism industry.
\end{abstract}

\section{Introduction}

With the development of economy and society and the continuous improvement of people's living standard, the role of sports in economic and social development has become more and more prominent, and sports tourism, as a sunrise industry, is an important industrial model to promote public health and enrich the leisure life of the masses.

Wudang Mountain, located in Danjiangkou, Shiyan City, Hubei Province, is a sacred Taoist site in China, also known as Taihe Mountain, rich in tourism resources, with excellent ecological environment, deep cultural heritage and characteristics, known as the world's first immortal mountain. In 1982, Wudang Mountain was listed by the State Council in the first batch of national key scenic spots, and in 1994 was listed by UNESCO in the World Cultural Heritage List. In 2007, Wudang Mountain was selected as one of the "Europeans' favorite ten scenic spots in China", and in 2010, Wudang Mountain was named as a national $5 \mathrm{~A}$ tourist scenic spot. Attracted by Wudang Wushu and Taoist culture, a large number of Chinese and foreign tourists travel to Wudang Mountain every year, and the area has a promising future for the Wushu tourism industry.

\section{SWOT analysis of Wudang Mountain Wushu tourism industry development}

\subsection{Advantage Analysis}

\subsubsection{Policy advantages}

The State General Administration of Sports has been promoting the development of sports tourism industry in recent years, and has organized the promotion of China Sports Tourism Excellence Projects for many years. At the 2020 China Sports Culture Expo, three projects in Hubei Province were awarded the China Sports Tourism Excellence Projects [1].

Table1. Selected projects in Hubei for the 2020 China Sports Tourism Excellence Projects

\begin{tabular}{|c|c|c|}
\hline No. & Category & Name of the project \\
\hline 1 & Travel Route & $\begin{array}{c}\text { Shennongiia Wildma } \\
\text { Pentathlon outdoor } \\
\text { experience routes }\end{array}$ \\
\hline 2 & Tourist Destination & Shennongjia Forest Area \\
\hline 3 & Tourist Scenic Area & $\begin{array}{c}\text { Luliangpo Ski and Alpine } \\
\text { Sports Resort Town, Enshi }\end{array}$ \\
\hline
\end{tabular}

\subsubsection{Deep cultural heritage}

First is Taoist culture. Wudang culture is deeply infiltrated by the Taoist philosophy, some of the ideological concepts and inherent traditions advocated by Taoism, such as the Tao of nature, quietness and inaction, the importance of people and noble life, integrity and goodness, the idea of the unity of heaven and man, and the harmony of heaven

\footnotetext{
*Corresponding author: 623256467@qq.com
} 
and earth, the harmony of yin and yang value core has long been respected. These are the main contents of the basic spirit of Wudang culture, which not only have an important influence on the behavior and habits of the people and the development of folk culture in the Wudang Mountain area, but also have a great impact on the development of traditional culture in China as a whole.

Second is architectural culture. Wudang Mountain scenic area is 312 square kilometers, with 53 surviving ancient buildings, 27,000 square meters of construction area, 9 architectural sites and 5,035 pieces of various cultural relics. The Wudang Mountain Taoist architecture group is a concentrated embodiment of Taoist culture in architecture, which emphasizes the harmony between man and nature and the harmony between architecture and environment, reflecting the harmonious thought of the ancient people of the unity of heaven and man.

Third is the culture of Wushu. Wudang Taijiquan, one of the trademarks of Wudang Wushu, moves with a combination of soft outside and firm inside, forming a unique set style of martial arts theory system and the health care value of Wudang taijiquan is becoming more popular among tourists at home and abroad. According to the World Taijiquan Development Report (2019), as an oriental cultural treasure, Taijiquan, after more than 300 years of inheritance and development, has now spread to more than 150 countries and regions, and the number of practitioners has reached 400 million.

Fourth is Wudang Daoist music. In 2006, Wudang Gongguan Daoist Music was approved by the State Council to be included in the first batch of national intangible cultural heritage list. Wudang Gongguan Daoist music is one of the ways of expressing religious beliefs in Taoism, as it is used throughout the activities of Taoist temples to pray for blessings from heaven, to subdue demons and exorcise the dead.

\subsubsection{Rich Wushu resources}

There are more than 30 Wushu schools in Wudang Mountain Special Zone, with tens of thousands of resident students. The number of Wushu schools may have increased or decreased slightly in recent years, but basically there is little change. The largest one belongs to Wudang Mountain International Wushu Academy of Wuhan Sports University, which covers an area of more than 1,000 Chinese acres, with a construction area of more than 100,000 square meters, competent faculty and advanced infrastructure. Other relatively large Wushu schools include Wudang Taoist Traditional School, Wudang Shi Xing Kung Fu School, and Wudang Mountain Chuanzhen Wushu Institute, all with a size of about 200 people, while other small Wushu schools range in size from a few to dozens of people [2].

Since the Wudang Mountain Special Zone founded the Wushu school in 1986, it has trained more than 100,000 Wudang disciples, including tens of thousands of foreign disciples, and has accumulated a certain foundation and experiences in running schools [3].

\subsubsection{Transportation and Geographical Advantages}

Shiyan is located in the center of the junction of four provinces, in the geometric center of the junction region of Hubei, Henan, Shaanxi and Chongqing, and between 300 and 700 kilometers from Wuhan, Xi'an, Chongqing and Zhengzhou. Due to the high attention of the state and the policy support of the province and city, the transportation construction of Wudang Mountain area in Shiyan has advanced rapidly in recent years, and a threedimensional rapid transportation network of land, railway and air has been formed. The convenient transportation network allows visitors from all over the country to easily choose the suitable way to reach Wudang Mountain faster.

\subsection{Disadvantage analysis}

\subsubsection{Tourism activities are not closely combined with Wushu elements}

Wudang Mountain tourist route mainly concentrates on natural landscape sightseeing, the process is relatively single and boring, and there is no significant difference compared with other conventional tourist attractions. The development of Wudang Mountain tourism route is not closely combined with Wudang Wushu elements, it can be said that a considerable part of tourists go to Wudang Mountain tourism is to be able to appreciate and feel the authentic Taoist culture and Wudang Wushu up close, however, field tourism is basically based on traditional scenery sightseeing. Although there are many Wushu schools and a large number of people practicing Wushu around the Wudang Mountain scenic area, the tourism industry does not make full use of this resource advantage to highlight the Wushu tourism elements or innovative tourism service supply. Tourists are generally walking around to see the scenery, wanting to get close to feel the Wushu, except for purchasing tickets to watch the large kung fu performance show in the Taiji Theater, they can only randomly see Taoist priests practicing or students doing exercises. There are no diversified Wushu tourism services to choose from.

\subsubsection{Insufficient cross-collaboration between Wushu events and tourism}

As mentioned above, Wudang Mountain has been promoting various Wushu events and arranging different Wushu competitions and performances on a regular basis, but the first problem is that Wushu events often target specific groups of people, such as athletes of participating sports teams, and do not have deep cooperation with the tourism sector, and there is a situation where competitions are competitions and tourism is tourism, and even tourists in the scenic area do not know or understand the ongoing Wushu events . Secondly, the kung fu show regularly staged has the problem of lack of interactive participation and experience of visitors. Third, the cross-collaboration of different industries is not enough, such as attractions, hotels, schools, training centers and so on do not form a good linkage or cooperation to launch the integration of 
innovative Wushu tourism service products, there is the phenomenon of fighting for each other's own battle.

\subsubsection{Insufficient promotional innovation and ineffective publicity}

In fact, Shiyan Municipal Government and Wudang Mountain Tourism Special Economic Zone attach great importance to the promotion of Wudang Wushu tourism industry. Publicity and promotion about Wudang Wushu are often seen in newspapers, magazines, TV and other print media and online media. However, the effect is limited. The reason for this is that apart from the impact of the massive publicity of emerging and fashionable sports, the lack of open-mindedness and innovation in the mode of publicity and promotion is also a problem that must be acknowledged.

\subsection{Opportunity Analysis}

\subsubsection{Strong policy support from Hubei Province}

The central government has been encouraging places to vigorously develop the service industry, the development of cultural tourism industry. In this context, Hubei Province has taken the initiative and responded positively by introducing relevant policies to support the development of tourism industry. 2020 and 2021, Hubei Province has issued successive documents and notices to promote the development of tourism industry with specific policy measures. Hubei also launched a number of tourism promotional activities provincewide to stimulate tourism consumption, achieving remarkable results.

\subsubsection{Tourism industry of Shiyan is developing rapidly and has great potential}

Shiyan is a city with large tourism resources, and the tourism industry is developing well. In the past few years, the scale of tourism industry has been expanding continuously, and the increase of tourism revenue has been climbing, with great potential and broad prospects for development. In 2020, Hubei launched the implementation of the "Tour Huibei with Love" campaign, Shiyan received 10 times and 13 times more than the same period in 2019, of which the Wudang Mountain received 39\% of the tourists from outside the province. In 2021, Shiyan has proposed to strive to receive 100 million domestic and foreign tourists, and the comprehensive income of tourism reaches 100 billion yuan [4].
Table2. Tourism reception data of Shiyan in 2020

\begin{tabular}{|c|c|c|c|}
\hline Table2. & Tourism reception data of Shiyan in 2020 \\
\hline 1 & $\begin{array}{c}\text { Reception of } \\
\text { visitors }\end{array}$ & $\begin{array}{c}80,163,000 \\
\text { person-times }\end{array}$ & $\begin{array}{c}\text { City-wide } \\
\text { annual data }\end{array}$ \\
\hline 2 & $\begin{array}{c}\text { Reception of } \\
\text { tourist groups }\end{array}$ & $\begin{array}{c}21,680 \text { tourist } \\
\text { groups, } \\
1,988,800 \\
\text { person-times }\end{array}$ & $\begin{array}{c}\text { August } 8 \text { to } \\
\text { December 31, } \\
2020\end{array}$ \\
\hline 3 & $\begin{array}{c}\text { Comprehensive } \\
\text { tourism income }\end{array}$ & $\begin{array}{c}82.2 \text { billion } \\
\text { yuan }\end{array}$ & $\begin{array}{c}\text { City-wide } \\
\text { annual data }\end{array}$ \\
\hline
\end{tabular}

\subsection{Threat Analysis}

\subsubsection{Fierce competition of tourism industry in the same city}

Shiyan is a major tourist city, with tourism being the second pillar industry. The region has two $5 \mathrm{~A}$ scenic spots and the number of 4A scenic spots is second only to Wuhan, reaching 14. Through years of efforts, Shiyan has formed a tourism cluster with a full set of functions such as sightseeing, leisure, vacation, experience and health care. While the tourism industry is flourishing, the competition between different tourism modes in the same city appears to be very intense.

\subsubsection{The scientific co-ordination planning of Wushu tourism development needs to be strengthened urgently}

The exquisite architecture of Wudang Mountain is majestic, and the magical natural landscape and the rich humanistic landscape are integrated into one, just like a fairyland on earth. However, in today's competitive tourism industry, Wudang Mountain, to a certain extent, there is still the idea of making a living in one's given circumstances, and there is a simple and brutal "circle of land and scenery to collect tickets" concept to develop tourism. In the development of Wushu tourism, although there are a few service models and products to provide, but relatively single, and the system is not complete. Nowadays, tourists' requirements for service quality of scenic spots are constantly increasing, and the scientific planning of Wushu tourism development needs to be strengthened.

\subsubsection{Insufficient composite professional talents in Wushu tourism industry}

Many colleges and universities in China set up sports majors and tourism majors, but due to the low degree of development of sports tourism in China, there are few colleges and universities that set up sports tourism as a major, and the time of setting up the major is also late, and to a certain extent, the experience is insufficient [5]. Specifically in the field of Wushu tourism, there is an even greater lack of composite professionals who understand both Wushu and tourism. Although there are several Wushu schools in the Wudang Mountain area, they mainly 
focus on training professional athletes and reserve talents in Wushu, and they do not offer sports tourism or Wushu tourism-related courses, which makes it difficult to provide targeted talent transfer to the tourism sector.

\section{Countermeasures}

\subsection{Multi-measures to boost publicity and promotion}

The main problem of Wudang Wushu tourism publicity is the lack of effect. Wudang Mountain should rapidly expand its influence through innovative publicity that brings together high traffic and attention. It is necessary to make a combination of publicity and promotion in the web portals, Weibo (Chinese Twitter-like social media platform), WeChat, online forums and video APPs. For instance, a Wudang Wushu tourism ambassador campaign can be arranged as annual event. Wudang Mountain can carry out promotional tourism short video clip awards, launch Wudang Wushu tourism star anchor support program and etc. Official agencies can also cooperate with mainstream APP developers to launch high-quality tourism APPs covering functions such as eating, staying, traveling, practicing, socializing and interacting, which deeply integrates Wushu elements to increase the participation rate and activeness of tourists. Only through targeted publicity measures can we achieve twice the effect of publicity with half the effort.

\subsection{Innovative service supply}

It is necessary to strengthen the deep integration of Wushu and tourism, highlight the core position of Wudang Wushu health culture [6], and vigorously develop Taiji practicing\&healing centers or other Wushu experiencebased tourism projects. There are many innovative service patterns that can be arranged such as providing short and medium hours of Wushu health experience classes in hotels, opening Wudang Taiji health visitor exchange forums, creating Wudang Wushu recreation and rehabilitation bases, etc. Through this innovative service supply and diverse service options, tourists can conveniently participate in Wudang martial arts sports, effectively interact with local martial arts practitioners and teachers, truly experience the charm of Wudang martial arts and Wudang culture, and gain a distinctive tourism experience. Wudang Mountain should keep making efforts to promote the development of regional tourism by innovating and providing rich martial arts tourism service products and continuously expanding the market with the optimal service.

\subsection{Increase the cultivation of tourism talents}

Wudang Mountain International Wushu Academy of Wuhan Sports University is located in the scenic spot, with first-class sports facilities, strong faculty, and a large number of young Wushu talents, which are quality higher education resources that most other scenic spots do not have. Therefore, in the process of Wudang Wushu tourism industry development, it should be pulled into the team to promote the industry development, strengthen the cross cooperation with tourism authorities, travel agencies, attractions, and hotels, and specifically cultivate more talents for the Wushu tourism industry [7].

\subsection{Improve the management level of scenic spots and tourism product planning ability}

Wudang Mountain area should continuously improve the management level of scenic spots, from tourism resource integration, product planning, development and construction to marketing and management services, fully optimize each link. It should take Wudang martial arts and Taoist culture as the selling point, work on the cultural connotation of tourism and martial arts elements, constantly improve the cultural essence and appeal of tourism, and in a true way promote the development of scenic spots, and this should be the long-term plan.

\section{Conclusion}

Amidst the background of the era of Building a Leading Sports Nation Strategy and Healthy China Initiative, and under the policy opportunity of the country vigorously promoting the development of sports tourism industry, Wudang Mountain, as a famous Taoist mountain renowned at home and abroad and the birthplace of Wudang Wushu, should seize the opportunity to deeply integrate Wushu elements into the regional tourism industry and create a composite multi-layer Wushu tourism industry pattern to better promote the industrial development. By giving full play to its own advantages and making up for its own shortcomings, Wudang Mountain will be able to achieve the goal of transformation and upgrading of the region's tourism industry and open up new horizons for the development of Wudang Wushu tourism industry.

\section{References}

1. China Sports Museum, Release of China Sports Tourism Excellence Projects, 2020.12, http://www.olympic.cn/museum/news/benguan/2020 /1229/371701.html

2. Pan Qin, et al. "Research on the current situation of Wudang Wushu development and inheritance countermeasures in Wudang Mountain area". Proceedings of the Chinese Wushu Research 2015 National Wushu Paper Presentation (above).Ed. , 2015, 266-271.

3. Shiyan Daily, Unveiling of Wudang Mountain International Wushu Academy, 2014.09, http://www.10yan.com/2014/0917/119367_2.shtml

4. Hubei Daily, 80.01 million visitors to Shiyan in 2020 , aiming over 100 million this year, 2021.2, http://news.hubeidaily.net/web/1542/202102/25/814 388.html 
5. Chen Jiali. SWOT analysis of developing sports tourism in Yangzhou city.2014. Yangzhou University, MA thesis.

6. Wu Zhiyong." Research on the development and countermeasures of Wudang Wushu tourism resources." Hubei Sports Science and Technology $32.09 \quad$ (2013):757-758+845. doi:CNKI:SUN:HYKJ.0.2013-09-001.

7. Yang Yang. Development and research of Wudang Wushu experiential tourism products.2016.Hubei University, MA thesis. 